OPEN ACCESS

Edited by:

Peter Lasch,

Robert Koch Institute, Germany

Reviewed by:

Daniel E. Voth,

University of Arkansas for Medical

Sciences, United States

Robert Heinzen,

National Institute of Allergy and

Infectious Diseases (NIAID),

United States

*Correspondence:

Jiri Dresler

jiri.dres/er@gmail.com

Specialty section:

This article was submitted to

Infectious Diseases,

a section of the journal

Frontiers in Microbiology

Received: 21 May 2019

Accepted: 19 August 2019

Published: 18 September 2019

Citation:

Dresler J, Klimentova J, Pajer P, Salovska B, Fucikova AM, Chmel M,

Schmoock G, Neubauer $H$ and Mertens-Scholz K (2019) Quantitative Proteome Profiling of Coxiella burnetii

Reveals Major Metabolic and Stress

Differences Under Axenic and Cell

Culture Cultivation.

Front. Microbiol. 10:2022.

doi: 10.3389/fmicb.2019.02022

\section{Quantitative Proteome Profiling of Coxiella burnetii Reveals Major Metabolic and Stress Differences Under Axenic and Cell Culture Cultivation}

\author{
Jiri Dresler ${ }^{1 *}$, Jana Klimentova ${ }^{2}$, Petr Pajer ${ }^{1}$, Barbora Salovska $^{3}$, \\ Alena Myslivcova Fucikova ${ }^{4}$, Martin Chmel ${ }^{5}$, Gernot Schmoock ${ }^{6}$, Heinrich Neubauer ${ }^{6}$ and \\ Katja Mertens-Scholz ${ }^{6}$
}

${ }^{1}$ Military Health Institute, Prague, Czechia, ${ }^{2}$ Faculty of Military Health Sciences, University of Defence, Hradec Kralove, Czechia, ${ }^{3}$ Department of Genome Integrity, Institute of Molecular Genetics of the Czech Academy of Sciences, Prague, Czechia, ${ }^{4}$ Department of Biology, Faculty of Science, University of Hradec Kralove, Hradec Kralove, Czechia, ${ }^{5}$ Department of Infectious Diseases, First Faculty of Medicine, Charles University and Military University Hospital Prague, Prague, Czechia,

${ }^{6}$ Institute of Bacterial Infections and Zoonoses, Friedrich-Loeffler-Institut, Jena, Germany

Coxiella burnetii is the causative agent of the zoonotic disease $Q$ fever. To date, the lipopolysaccharide (LPS) is the only defined and characterized virulence determinant of $C$. burnetii. In this study, proteome profiles of $C$. burnetii Nine Mile phase I (RSA 493, NMI) and its isogenic Nine Mile phase II (RSA 439 NMII) isolate with a deep rough LPS were compared on L-929 mouse fibroblasts and in complex (ACCM-2), and defined (ACCM-D) media. Whole proteome extracts were analyzed using a label-free quantification approach. Between 659 and 1,046 C. burnetii proteins of the 2,132 annotated coding sequences (CDS) were identified in any particular experiment. Proteome profiles clustered according to the cultivation conditions used, indicating different regulation patterns. NMI proteome profiles compared to NMII in ACCM-D indicate transition from an exponential to a stationary phase. The levels of regulatory proteins such as RpoS, CsrA2, UspA1, and UspA2 were increased. Comparison of the oxidative stress response of $\mathrm{NMI}$ and NMII indicated that ACCM-2 represents a high oxidative stress environment. Expression of peroxidases, superoxide dismutases, as well as thioredoxins was increased for NMI. In contrast, in ACCM-D, only osmoregulation seems to be necessary. Proteome profiles of NMII do not differ and indicate that both axenic media represent similar oxidative stress environments. Deep rough LPS causes changes of the outer membrane stability and fluidity. This might be one reason for the observed differences. Proteins associated with the T4SS and Sec translocon as well as several effector proteins were detectable under all three conditions. Interestingly, none of these putatively secreted proteins are upregulated in ACCM-2 compared to ACCM-D, and L-929 mouse fibroblasts. Curiously, a higher similarity of proteomic patterns (overlapping up- and downregulated proteins) of ACCM-D and 
bacteria grown in cell culture was observed. Particularly, the proteins involved in a better adaptation or homeostasis in response to the harsh environment of the parasitophorous vacuole were demonstrated for NMI. This semi-quantitative proteomic analysis of C. burnetii compared axenically grown bacteria to those propagated in cell culture.

Keywords: Coxiella burnetii, axenic culture, semi-quantitative proteomics, oxidative stress response, type IV B secretion system, dot/icm, Sec translocon, proteome

\section{INTRODUCTION}

Coxiella burnetii, a Gram-negative and obligate intracellular bacterium, is the etiological agent of query (Q) fever. This almost worldwide-distributed zoonotic disease manifests as an acute, flu-like illness or as a potentially lifethreatening chronic disease in humans (Maurin and Raoult, 1999). C. burnetii has a broad host spectrum (Angelakis and Raoult, 2010) and the bacteria are transmitted via inhalation of contaminated aerosols.

Coxiella burnetii passively enters its primary target cells, alveolar macrophages, and traffics through the endocytic cascade (Graham et al., 2013). The intracellular niche, named Coxiellacontaining vacuole (CCV), shows all characteristics of a terminal phagolysosome, but is actually a highly specific, and pathogen-directed niche. C. burnetii employs a type IV B secretion system (T4SS), also known as Dot/Icm (defect in organelle trafficking/intracellular multiplication) apparatus, to secrete effector proteins into the cytosol of the host (Zamboni et al., 2003; Chen et al., 2010). To date, more than 100 effectors have been described, but only few of them are known to subvert the host cell-signaling pathways, including vesicle trafficking, apoptosis, autophagy, and immune responses, to ensure intracellular survival of C. burnetii (Larson et al., 2013; Moffatt et al., 2015; Mansilla Pareja et al., 2017; Schäfer et al., 2017; Weber et al., 2018). Within the CCV, bacteria are exposed to a variety of anti-microbial agents such as oxidative stress, low $\mathrm{pH}$, defensins, and proteases (Voth and Heinzen, 2007; van Schaik et al., 2013). C. burnetii is highly adapted to this unique niche and employs several antioxidative stress strategies, such as expression of DNA repair genes and detoxification of reactive oxygen species (ROS) and reactive nitrogen species (RNS) released by the host (Briggs et al., 2008; Mertens et al., 2008; Siemsen et al., 2009; Hill and Samuel, 2011; Brennan et al., 2015).

Upon frequent passaging in immune incompetent hosts or axenic cultivation, C. burnetii undergoes a phase variation (Hackstadt et al., 1985). This variation is characterized by a decreasing length of the O-antigen of the lipopolysaccharide (LPS) accompanied by a loss in virulence (Ftácek et al., 2000; Andoh et al., 2005; Beare et al., 2018). From the C. burnetii Nine Mile strain, two clonal isolates exist: virulent phase I (RSA 493, clone 7, NMI) with a full-length LPS, and avirulent phase II (RSA 439, clone 4, NMII) with a deep rough LPS. The major difference between these clones is a deletion of $\sim 26 \mathrm{~kb}$ within a genome region associated with LPS biosynthesis (Hoover et al., 2002; Millar et al., 2017).
C. burnetii isolates display genetic heterogeneity and circulating predominant genotypes have been described (Hendrix et al., 1991; Chmielewski et al., 2009; Russell-Lodrigue et al., 2009; Roest et al., 2011; Boarbi et al., 2014; Frangoulidis et al., 2014). Observed differences in the pathogenic potential of isolates may be the result of either a variable repertoire of virulence factors or due to predisposed immunological properties of the host. Thus, genetic differences have to be validated by classical genetic approaches and on the proteomic level. With the development of an axenic cultivation method, genetic modification, growth behavior, and production of whole-cell antigen free from host material for genome sequencing or proteome analyses became feasible (Omsland et al., 2009; Sandoz et al., 2016a).

A genome-wide transcriptional study comparing in vivo model (mice) with in vitro cell-based and cell-free cultivation revealed major differences in expression, but the corresponding proteomic study is still missing (Kuley et al., 2015a). Previous proteomic studies based on gel electrophoresis compared NMI and NMII grown in embryonated hen eggs (Skultety et al., 2005, 2011; Samoilis et al., 2007) and identified tetracycline resistance mechanisms or virulence-associated proteins (Samoilis et al., 2010; Flores-Ramirez et al., 2014).

Major drawbacks of the gel-based approaches are that relatively high amount of protein sample is needed and also their labor-intensiveness. Moreover, labeling-based techniques are limited by the need of expensive consumables, an inability to add further samples into the experiment, and a limited number of comparable groups (Megger et al., 2013). On the contrary, labelfree quantification (LFQ) does not require any labeling step, and relies only on spectral counting or MS intensity of peptide signal of the quantified feature.

The aim of the presented study is to determine differences in proteome profiles of $C$. burnetii under axenic cultivation and cell culture propagation by quantitative proteomics. We choose the isogenic strains NMI and NMII for comparison. These differ only in length of the LPS, replicate in indistinguishable CCVs, and show similar growth rates in primary monocytederived macrophages (Howe et al., 2010) and THP-1 cells. However, NMII fails to replicate in immunocompetent mice (Andoh et al., 2005) and NMII LPS does not confer protection in challenge experiments (Zhang et al., 2007). The LPS plays an important physiological role, besides barrier against antibiotics or host defense factors. It stabilizes the membrane due to the interaction of the O-polysaccharide portion and binding of divalent cations. Deep rough LPS leads to the accumulation of phospholipid patches, higher membrane fluidity, and higher 
permeability for lipophilic compounds. Further, truncation of the LPS affects correct folding and insertion of outer membrane proteins (OMPs) (Nikaido, 2003; Wang et al., 2015). Based on quantitative comparison of NMI and NMII in vitro, we want to establish a method to connect genomic data with expression profiles for identification of isolate-specific traits that will support the described isolate-specific virulence pattern. Therefore, we performed semi-quantitative analysis of NMI and NMII propagated in two different axenic media and in L-929 mouse fibroblasts employing an LFQ approach.

\section{MATERIALS AND METHODS}

\section{Bacterial Strains and Growth Conditions}

C. burnetii Nine Mile phase I (RSA 493, NMI) and phase II (RSA 439, NMII) propagated in L-929 mouse fibroblasts were used for inoculation of axenic acidified citrate cysteine medium 2 (ACCM-2) and defined ACCM (ACCM-D) as described previously (Omsland et al., 2011; Sandoz et al., 2016a; Sanchez et al., 2018). Briefly, 1-l cultures were inoculated with $1 \mathrm{E}+05 \mathrm{GE} / \mathrm{ml}$ (genome equivalents) and incubated until they reached a density of $1 \mathrm{E}+07$ to $1 \mathrm{E}+08 \mathrm{GE} / \mathrm{ml}$ at $37^{\circ} \mathrm{C}$ with $5 \%$ $\mathrm{CO} 2$ and $2.5 \% \mathrm{O} 2$. This was archived after 7 or 10 days in ACCM2 and ACCM-D. Cultures were harvested by centrifugation $\left(21,200 \times g ; 15 \mathrm{~min} ; 4^{\circ} \mathrm{C}\right)$ and resuspended in $270 \mathrm{mM}$ sucrose solution containing $10 \%(\mathrm{v} / \mathrm{v})$ glycerol for storage at $-80^{\circ} \mathrm{C}$. For propagation of C. burnetii in L-929 mouse fibroblasts (DMEM medium, 5\% heat inactivated fetal bovine serum), cells were inoculated with a multiplicity of infection (MOI) of 100 and incubated at $37^{\circ} \mathrm{C}$ and $5 \% \mathrm{CO} 2$. Infection was visually assessed and cultures were harvested when nearly $80 \%$ of cells were infected. Briefly, cell layers were scraped, centrifuged $(1,000 \times$ $g$, $5 \mathrm{~min}, 4^{\circ} \mathrm{C}$ ), and resuspended in $1 \mathrm{ml}$ of $270 \mathrm{mM}$ sucrose solution containing $10 \%(\mathrm{v} / \mathrm{v})$ glycerol for storage at $-80^{\circ} \mathrm{C}$. All laboratory procedures involving the handling of live bacteria of NMI were carried out in a Biosafety Level 3 laboratory.

\section{DNA Isolation and Quantification by Real-Time PCR (qPCR)}

Bacterial quantification was carried out as previously described by real-time PCR (qPCR) using the isocitrate dehydrogenase encoding gene (icd) as target (Klee et al., 2006). Detailed description of the procedure is described in the Supplementary Methods section.

\section{Proteomic Sample Preparation}

The bacterial cells from axenic media and L-929 cell-based cultures (Table S1) were pelleted by centrifugation $(18,000 \times g$; $20 \mathrm{~min} ; 4^{\circ} \mathrm{C}$ ) and washed with $300 \mu \mathrm{l}$ of phosphate-buffered saline (PBS, $\mathrm{pH}$ 7.4). The resulting pellets were resuspended in $0.1 \%$ RapiGestTM SF (Yu et al., 2003) (Waters, Manchester,

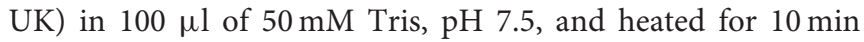
at $95^{\circ} \mathrm{C}$. After cooling down, $200 \mu \mathrm{l}$ of $0.1 \%$ RapiGestTM SF in $8 \mathrm{M}$ guanidinium chloride (Sigma-Aldrich) was added an incubated for $20 \mathrm{~min}$. The protein sample(s) were stored at $-80^{\circ} \mathrm{C}$ until samples were proven free of viable bacteria. Because of the potential of interfering substances in the supernatant, the following sample preparation workflow was applied and based on Filter aided sample preparation (FASP) (Wiśniewski et al., 2009). Briefly, inactivated samples were transferred onto Amicon ${ }^{\circledR}$ Ultra 10-kDa filters (Millipore) and washed twice with $100 \mathrm{mM}$ ammonium bicarbonate (Sigma-Aldrich). Subsequently, proteins were quantified by bicinchoninic acid assay (QuantiPro ${ }^{\mathrm{TM}}$ BCA Assay Kit, Sigma-Aldrich) (Smith et al., 1985; Table S1). The samples were then reduced with $100 \mathrm{mM}$ Tris (2-carboxyethyl) phosphine hydrochloride (TCEP, Sigma-Aldrich) and alkylated with $300 \mathrm{mM}$ iodoacetamide (Sigma-Aldrich). Finally, the samples were digested with 2 $\mu \mathrm{g}$ of sequencing grade trypsin (Promega) overnight at $37^{\circ} \mathrm{C}$. Empore $^{\mathrm{TM}}$ SPE Cartridges, C18, standard density, bed I.D. $4 \mathrm{~mm}$ (Sigma-Aldrich) were used to desalt peptide mixtures before drying to completion in a speed-vac. Before mass spectrometry analysis, the samples were resuspended in $30 \mu \mathrm{L}$ of $2 \%$ acetonitrile $(\mathrm{ACN}) / 0.1 \%$ trifluoroacteic acid. The samples were further analyzed by LC-MS/MS techniques involving targeted mass spectrometry and LFQ. Detailed description of procedure of proteomic sample preparation and data processing is described in the Supplementary Methods section.

\section{Evaluation of Up- and Downregulated Proteins Under Axenic Cultivation and Under Cell Culture Propagation}

The selection was based on a combination of functional annotation enrichment analysis and further statistical techniques as described below. The imputation of missing values from a normal distribution (Gaussian distribution width $0.3 \mathrm{SD}$ and down-shift 1.8 SD of the original data) was performed, and proteins were annotated by Gene Ontology (GO) terms and UniProt (www.uniprot.org) keywords for C. burnetii (strain RSA 493/Nine Mile phase I, downloaded on April 2, 2016, 1,816 sequences). For comparison of axenic media replicates, ANOVA (permutation-based FDR 5\%, S0 =0) was used to identify significant differences in protein expression between individual groups. For comparison of cell-based cultures, Student's $t$-test was applied to identify proteins differentially expressed between NMI- and NMII-infected L-929 sample groups at a 5\% threshold, and a permutation-based FDR was applied at a 5\% threshold. Only ANOVA significant/Student's $t$-test significant hits were included for subsequent hierarchical clustering using Euclidean distances to group proteins with similar expression profiles.

\section{RESULTS}

Using the LFQ approach described in this study, between 659 and 1,046 C. burnetii proteins of 2,132 annotated CDS (coding sequences) were identified in each sample (Table S1). For NMI and NMII propagated in both axenic media (ACCM-2 and ACCM-D), a total of 1,075 quantifiable proteins specific for C. burnetii were detected and analyzed (Table S2). In L-929 cell-based cultures, a total of 906 C. burnetii-specific proteins were quantifiable and were identified (Table S3). The observed quantities of the proteins are depicted as $\log 2$ transformation of LFQ intensities and include the values imputed by Perseus-type 
value imputation (Cox et al., 2011, 2014). The values ranging from 21 to 32 reflect the dynamic range of the mass spectrometrybased workflow. Among these proteins, 772 were significantly up- or downregulated (ANOVA test, $q \leq 0.05$ ) in axenic media experiments and 119 were significantly different (Student's $t$-test, $q \leq 0.05$ ) in cell-based experiments (Tables S2, S3).

Pathway mapping of proteins identified under different culture conditions (ACCM-2, ACCM -D, cell culture) was done with PANTHER classification tool (Thomas, 2003; Mi et al., 2013) (ver. 14.1). For each culturing condition, roughly 50\% of the identified proteins could be assigned to a biological pathway, as shown in Figure 1A. For ACCM-2 cultivation, 660 of 1,055 quantifiable proteins were assigned to various biological processes. Similar results were obtained for ACCM-D with 661 of 1,047 quantifiable proteins and for cell culture samples with 578 of 906 quantifiable proteins with functional assignment. Cellular component analysis showed that 337 proteins from bacteria cultivated in ACCM-2, 339 from ACCM-D, and 290 from cell culture were assigned. Most other proteins are without any annotated function or without cellular component assignment (Figure 1A).

\section{Comparison of Proteomes of Individual Experiments}

To assess the applicability of the LFQ approach, we examined the similarity of individual proteomes using hierarchical clustering and principal component analysis (PCA). Unsupervised cluster analysis of protein expression profiles was performed using Euclidean distances. Statistical procedures were performed using the computational platform Perseus (Cox et al., 2014). Both hierarchical clustering (Figure 1B) and PCA (Figure 1C) generated six distinctive groups encompassing each biological triplicate of analyzed C. burnetii phase variant under different conditions. Differences in proteome profiles are predominant between axenic grown and tissue culture propagated bacteria. Proteomes of NMI and NMII grown in ACCM-2 and ACCM$\mathrm{D}$ clustered more closely together than proteomes of L929 propagated bacteria (Figure 1D). Only proteins whose expression is significantly different (ANOVA, $q \leq 0.05$ ) in axenic media conditions and significantly different in cell-based experiment (Student's $t$-test, $q \leq 0.05$ ) were further evaluated. As demonstrated in Figure 1D, cultivation in ACCM-D and L929 revealed 50 common upregulated proteins, whereas only 10 were common between ACCM-2, and L-929. A similar trend was observed for the downregulated group of proteins: under ACCM-D and L-929 culture conditions, the same six proteins were downregulated, whereas only two were common for ACCM-2 and L-929 (Figure 1E). These data imply the applicability of the established workflow for the analysis of total protein expression.

\section{C. burnetii Proteome Profiles Differ Accordingly to Their Growth Condition and Growth State}

Proteome analyses were performed with C. burnetii NMI and NMII cultures, propagated in ACCM-2 and ACCM-D until a density of $1 \mathrm{E}+07$ to $1+\mathrm{E} 08 \mathrm{GE} / \mathrm{ml}$ was observed, respectively (Table S1). Infected L-929 mouse fibroblasts were cultured until nearly $80 \%$ of cells were visually positive for C. burnetiicontaining vacuoles (CCV). Under these three groups, NMI, and NMII showed different proteome profiles accordingly to the growth media used and thus imply different growth states or stress conditions.

\section{Proteome Profiles of NMI Compared to NMII in ACCM-D Resemble a Stationary Phase Growth Pattern}

For NMI compared to NMII propagated in ACCM-D or ACCM2, a total of 607, and 305 up- or downregulated proteins were detected, respectively. In ACCM-D, 292 proteins were upregulated and 315 were downregulated in NMI compared to NMII. In ACCM-2, only 115 upregulated and 190 downregulated proteins were detected in NMI compared to NMII.

The comparison of NMI with NMII in ACCM-D indicates a stationary phase growth pattern for NMI. Many proteins of the translation machinery, such as $50 \mathrm{~S}$ and $30 \mathrm{~S}$ ribosomal subunit proteins, translation initiation factors (IF-2, IF-3), translation elongation factors (EF-G, EF-Ts), and ribosomal maturation factor RbfA as well as the ribosome-associated inhibitor A (RaiA, CBU_0020) are downregulated. CsrA2 (CBU_1050), a stress response regulator, is upregulated. In addition, caseinolytic proteases (Clp, chaperon), such as $\mathrm{ClpA}$ and ClpP-like proteins CBU_0353, CBU_1483, and CBU_1538, were upregulated for NMI in ACCM-D.

Exponential phase transcriptional factors Fis and RpoD are downregulated. RpoS, the primary sigma factor during stationary phase, and SpoT, which positively regulates rpoS expression, are upregulated in NMI compared to NMII grown in ACCM-D.

Several proteins associated with cell wall remodeling are upregulated in NMI compared to NMII in ACCM-D. CopB (CBU_0092), which coordinates peptidoglycan synthesis and outer membrane constriction during cell division, was upregulated. Further, several peptidoglycan and cell wall biogenesis proteins, including the previously described CBU_0419, CBU_0925, EnhB.1, EnhC, EnhA.4, and EnhA.5, were upregulated in NMI compared to NMII in ACCM-D (Sandoz et al., 2016b).

Three out of 16 LCV-associated proteins, CBU_0658 (unknown function), Bcp, and UspA1, stress associated proteins, were over 2-fold upregulated in NMI compared to NMII in ACCM-D (McCaul et al., 1991; Seshadri et al., 1999; Varghees et al., 2002; Coleman et al., 2007; Hicks et al., 2010; Sandoz et al., 2016b). Similar results were obtained for SCV-associated proteins. Two proteins of unknown function, CBU_0961 and CBU_1561, as well as the SCV-specific protein ScvA were >2-fold upregulated in ACCM-D for NMI compared to NMII (McCaul et al., 1991; Heinzen et al., 1992; Varghees et al., 2002; Coleman et al., 2007).

An overview of selected proteins indicating a stationary growth pattern for NMI compared to NMII in ACCM-D, including their fold changes, are listed in Table 1. Taken together, these data lead to the hypothesis that some proteins of NMI 


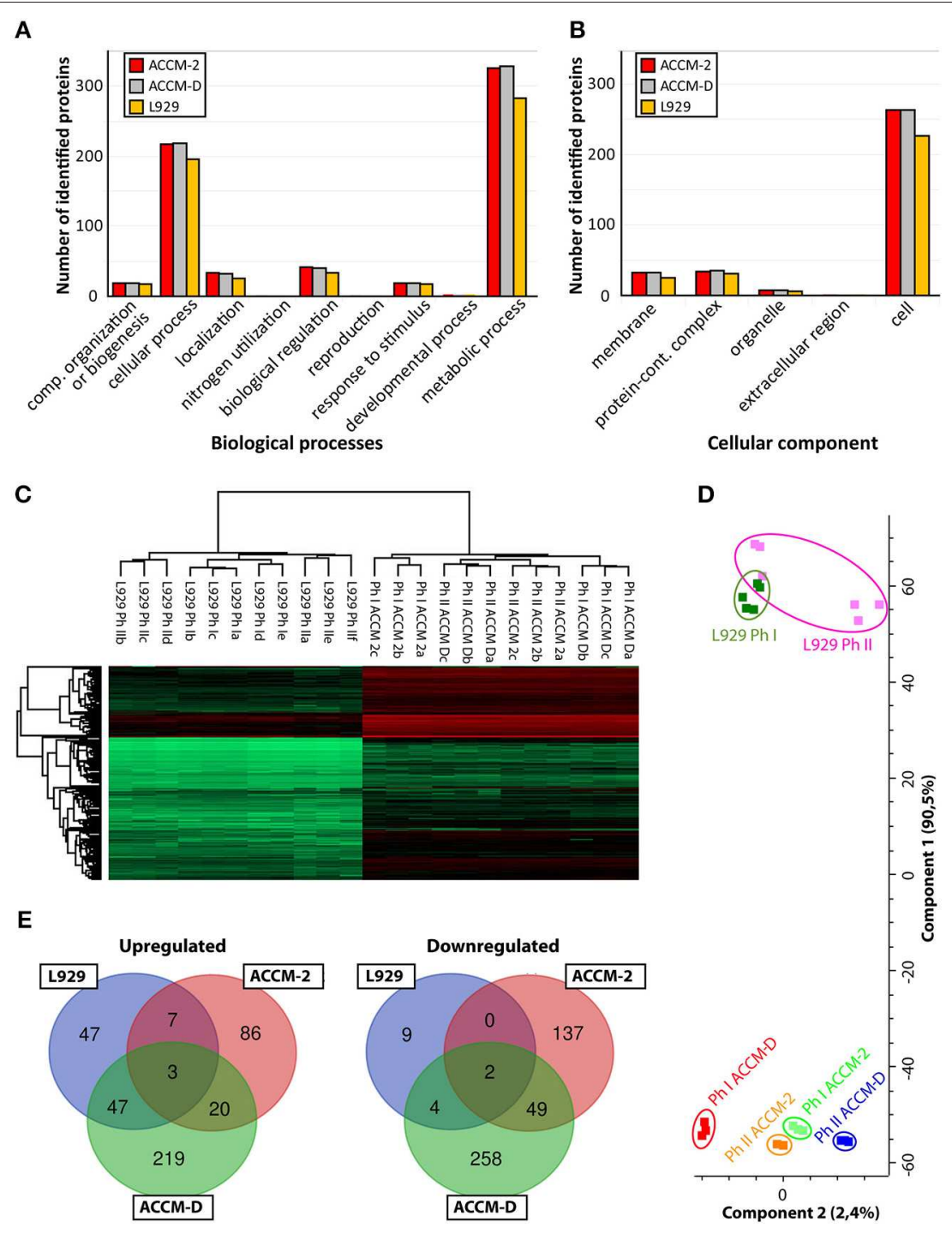

FIGURE 1 | Overview of C. burnetii proteome profiles under three different culture conditions. (A) Mapping of biological pathways utilized by C. burnetii during ACCM-2, ACCM-D, or L-929 propagation and (B) mapping. (B) Mapping of cellular component assignment utilized by C. burnetii during ACCM-2, ACCM-D, or L-929 propagation using the PANTHER classification tool. (C) Hierarchical clustering of protein expression values based on label-free proteome quantification. LFQ values vs. biological replicates (designated as a, b, and c, or up to f for L929-based experiments) from particular samples. The color code indicates the LFQ values abundance of the quantifiable proteins (red, most abundant; green, least abundant). (D) Principal component analysis (PCA) of the LFQ intensities obtained from biological replicates of each representative group. (E) The number of statistically significant upregulated (left) and downregulated (right) proteins of $C$. burnetii Nine Mile phase I compared to C. burnetii Nine Mile phase II. Overlapping regions or identifications indicate up- or downregulated proteins under more than one culture condition.

compared to NMII propagated in ACCM-D seem to mimic transition from an exponential to a stationary phase.

Proteome Profiles of NMI Compared to NMII in ACCM-2 Reveals No Major Differences.

Overall, proteome analysis of ACCM-2-grown bacteria identified a smaller number of regulated proteins when comparing NMI to NMII. The 115 upregulated or 190 downregulated proteins in NMI compared to NMII indicated no specific growth phase. Regulations of proteins associated with the translational machinery, post-translational modification (chaperons), as well as co-factor synthesis were partly up- and downregulated. Interestingly, the ATP synthase (AtpA, AtpD, AtpG, AtpF) was upregulated in NMI compared to NMII in ACCM-2. These data imply the absence of major metabolic differences of NMI and NMII grown in ACCM-2.

\section{NMI and NMII Respond Differently to Stress in Axenic Media and Cell Culture}

Comparison of the proteome profiles of NMI with NMII, propagated in either ACCM-2 or ACCM-D, shows major differences in response to oxidative stress. In ACCM-2, the alkyl hydroperoxide reductases AhpC1 and AhpC2, cytoplasmic 
TABLE 1 | Overview of selected C. burnetii proteins involved in entering of NMI into the stationary phase in ACCM-D.

\begin{tabular}{|c|c|c|c|c|c|c|c|c|}
\hline & \multirow[t]{2}{*}{ Locus } & \multirow[t]{2}{*}{ Protein } & \multirow[t]{2}{*}{ Function } & \multicolumn{3}{|c|}{ NMI to NMII } & \multirow{2}{*}{$\begin{array}{c}\text { NMI } \\
\text { ACCM-D to } \\
\text { ACCM-2 }\end{array}$} & \multirow{2}{*}{$\begin{array}{c}\text { NMII } \\
\text { ACCM-D to } \\
\text { ACCM-2 }\end{array}$} \\
\hline & & & & ACCM-D & ACCM-2 & L-929 & & \\
\hline \multirow[t]{6}{*}{ Regulation } & CBU_0303 & SpoT & GTP pyrophosphokinase & 3.59 & 1.46 & $\mathrm{NaN}$ & 1.59 & 0.65 \\
\hline & CBU_1050 & CsrA2 & Translational regulator & 0.10 & 0.13 & 1.53 & 2.89 & 3.72 \\
\hline & CBU_1596 & RpoD & Sigma factor & 0.60 & 0.63 & 0.97 & 1.01 & 1.06 \\
\hline & CBU_1669 & Rpos & Sigma factor & 0.62 & 0.36 & 0.75 & 659.15 & 382.27 \\
\hline & CBU_1916 & UspA2 & Universal stress protein & 3.25 & 0.17 & 0.61 & 5.82 & 0.30 \\
\hline & CBU_1983 & UspA1 & Universal stress protein & 2.14 & 0.49 & 3.13 & 2.24 & 0.51 \\
\hline \multirow[t]{4}{*}{ Chaperon } & CBU_0353 & & ClpP-like protein & 21.28 & 0.43 & 2.54 & 24.49 & 0.49 \\
\hline & CBU_1196 & ClpA & ATP-dependent clp protease ATP-binding subunit & 1972.42 & 0.00 & 0.83 & 912.01 & 0.00 \\
\hline & CBU_1483 & & ClpP-like protein & 5.73 & 0.09 & 13.40 & 6.62 & 0.10 \\
\hline & CBU_1538 & & ClpP-like protein & 1.44 & 0.48 & 0.76 & 1.29 & 0.43 \\
\hline \multirow[t]{6}{*}{ Cell envelope } & CBU_0419 & & Polysaccharide deacetylase family & 629.51 & 0.07 & 0.19 & 81.28 & 0.01 \\
\hline & CBU_0915 & EnhB.1 & Enhanced entry protein & 19.05 & 0.17 & 6.76 & 26.48 & 0.23 \\
\hline & CBU_0925 & & Membrane-bound lytic murein transglycosylase B & 2133.04 & 0.06 & 8.83 & 521.19 & 0.01 \\
\hline & CBU_1136 & EnhC & Enhanced entry protein & 492039.54 & 0.00 & 10.69 & 2157744.41 & 0.00 \\
\hline & CBU_1138 & EnhA.4 & Enhanced entry protein & 13997.48 & 0.02 & 8.57 & 4324.11 & 0.01 \\
\hline & CBU_1394 & EnhA.5 & Enhanced entry protein & 1277.54 & 0.15 & 35.67 & 1045.55 & 0.13 \\
\hline \multirow[t]{3}{*}{ SCV } & CBU_0961 & & Unknown & 0.41 & 0.25 & $\mathrm{NaN}$ & 2.99 & 1.84 \\
\hline & CBU_1267.1 & ScvA & SCV-specific protein ScvA & 346928.52 & 0.00 & 13.00 & 328256.50 & 0.00 \\
\hline & CBU_1561 & & Unknown & 225.94 & 0.37 & $\mathrm{NaN}$ & 706.32 & 1.15 \\
\hline
\end{tabular}

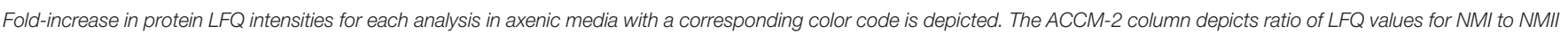

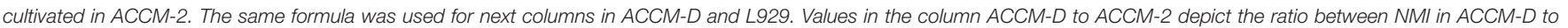

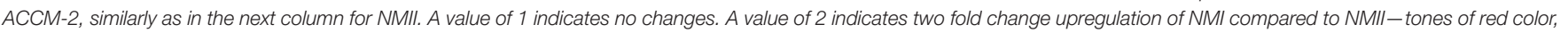

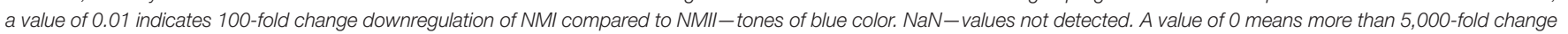
downregulation of NMI compared to NMII (the values are rounded).

superoxide dismutase B (SodB), and the periplasmic SodC are over 2-fold upregulated for NMI compared to NMII. In addition, glutathione (GshAB, glutathione synthesis) and a glutaredoxinlike protein (CBU_0583) are upregulated in NMI compared to NMII when propagated in ACCM-2. On the contrary, both AhpCs are downregulated in NMI compared to NMII when propagated in ACCM-D.

Upregulation of a glycine betaine transport system, CBU_0177/CBU_0178, in NMI compared to NMII propagated in ACCM-D implies an active osmoregulation. Interestingly, the same upregulation was detected for NhaP.1, a $\mathrm{Na} 2+/ \mathrm{H}+$ antiporter that extrudes sodium in exchange for external protons. During propagation in L-929 mouse fibroblasts, most oxidative stress response proteins are upregulated as well as the glycine betaine transport system when comparing NMI to NMII. An overview of selected C. burnetii proteins involved in stress response of NMI and NMII in axenic media and cell culture, including their fold changes, is provided in Table 2.

\section{Proteins Potentially Involved in Sec Translocation Are Upregulated in NMI}

Components of the Sec-TolC pathway (SecABDFY, YajC, YidC, Fth, FtsY, LepB-1, and LepB-2, TolC) and previously described 24 Sec-secreted proteins were detected in samples harvested from axenic medium and cell culture. Additionally, two putatively secreted proteins, CBU_0110 and CBU_1764a, were only detectable in samples from cell culture but not from axenic media. Interestingly, potentially Sec-secreted proteins were upregulated in NMI compared to NMII in ACCM-D, but not in ACCM-2.

Other transporters, such as several ABC transporters, RND efflux pumps, AcrB-like efflux systems, and MFS superfamily transporters were upregulated during propagation in L-929 and ACCM-D for NMI compared to NMII. An overview of selected C. burnetii proteins involved in secretion systems in axenic media and cell culture is provided in Table 3.

\section{Type IV B Secretion System and Effectors Are Expressed in Axenic Media and Cell Culture}

Most components of the T4BSS were expressed under axenic and cell culture conditions. Only two structural components, $\mathrm{IcmD}$ and $\mathrm{IcmH}$, were not detected in axenically grown bacteria. Additionally, four components, IcmD, IcmH, IcmT, and IcmC/DotE, were not detected in L-929 propagated bacteria. IcmB (DotP), IcmE (DotG), IcmG (DotF), IcmH, IcmK (DotH), IcmL.1, IcmL.2, IcmN (DotK), IcmO (DotL), and IcmX were found upregulated in NMI during L-929 infection when 
TABLE 2 | Overview of selected C. burnetii proteins involved in different responses of NMI and NMII to stress in axenic media and cell culture.

\begin{tabular}{|c|c|c|c|c|c|c|c|c|}
\hline & \multirow[t]{2}{*}{ Locus } & \multirow[t]{2}{*}{ Protein } & \multirow[t]{2}{*}{ Function } & \multicolumn{3}{|c|}{ NMI to NMII } & \multirow{2}{*}{$\begin{array}{c}\text { NMI } \\
\text { ACCM-D to } \\
\text { ACCM-2 }\end{array}$} & \multirow{2}{*}{$\begin{array}{c}\text { NMII } \\
\text { ACCM-D to } \\
\text { ACCM-2 }\end{array}$} \\
\hline & & & & ACCM-D & ACCM-2 & L-929 & & \\
\hline \multirow[t]{11}{*}{ Oxidative stress } & CBU_0583 & & Glutaredoxin & 0.30 & 8.26 & 0.74 & 0.04 & 1.03 \\
\hline & CBU_0963 & $\mathrm{Bcp}$ & Putative peroxiredoxin bcp & 1.81 & 0.57 & 3.88 & 2.30 & 0.72 \\
\hline & CBU_1193 & $\operatorname{TrxB}$ & Thioredoxin reductase & 0.61 & 1.72 & 1.97 & 0.53 & 1.50 \\
\hline & CBU_1476 & OxyR & Hydrogen peroxide-inducible genes activator & 0.53 & 1.66 & 2.99 & 0.35 & 1.10 \\
\hline & CBU_1477 & AhpC2 & Hydroperoxide reductase & 0.37 & 17.89 & $\mathrm{NaN}$ & 0.04 & 1.73 \\
\hline & CBU_1706 & AhpC1 & Hydroperoxide reductase & 0.53 & 2.48 & 1.55 & 0.25 & 1.20 \\
\hline & CBU_1708 & SodB & Superoxide dismutase B & 4.64 & 2.19 & 0.71 & 2.09 & 0.98 \\
\hline & CBU_1822 & SodC & Superoxide dismutase C & 3.95 & 11.32 & 2.56 & 0.00 & 0.00 \\
\hline & CBU_1874 & GshA & Glutamate-cysteine ligase & 1.74 & 5.46 & 3.07 & 0.27 & 0.83 \\
\hline & CBU_1875 & GshB & Glutathione synthetase & 6.46 & 5.18 & 855.89 & 0.60 & 0.48 \\
\hline & CBU_2087 & $\operatorname{Tr} x$ & Thioredoxin & 1.57 & 0.54 & 1.77 & 2.70 & 0.93 \\
\hline \multirow[t]{3}{*}{ Osmoregulation } & CBU_1259 & NhaP.1 & $\mathrm{Na}+/ \mathrm{H}+$ antiporter & 77.91 & 0.12 & $\mathrm{NaN}$ & 60.25 & 0.09 \\
\hline & CBU_0177 & & Glycine betaine transport system permease protein & 5.60 & 1.95 & 5.77 & 1.37 & 0.48 \\
\hline & CBU_0178 & & Glycine betaine transport ATP-binding protein & 4.35 & 2.54 & 6.63 & 0.85 & 0.50 \\
\hline
\end{tabular}

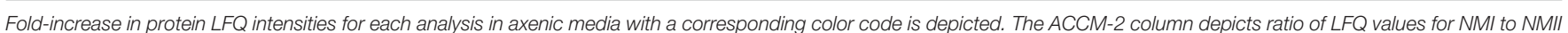

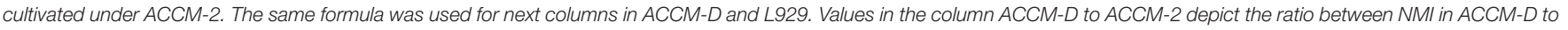

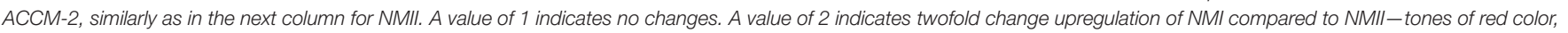

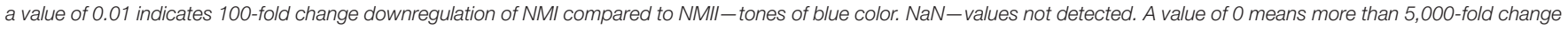
downregulation of NMI compared to NMII (the values are rounded).

compared to NMII. IcmX, a secreted/released T4BSS protein (Luedtke et al., 2017), was upregulated exclusively in NMI under all cultivation conditions.

In our study, PmrA was expressed nearly two orders of magnitude higher in NMI compared to NMII when propagated in L-929. A similar upregulation of PmrA was found for NMI in ACCM-2, but not in ACCM-D. PmrB was also detected 1.5 times higher in NMI compared to NMII during propagation in L-929.

The detected amount of DotA (Luedtke et al., 2017) was not significantly changed during infection of L-929 and cultivation in ACCM-D for both isolates. On the contrary, the level of DotA was decreased in NMI compared to NMII in ACCM-2. Regarding some other T4BSS proteins, DotB, DotC, and DotD, no significant differences between NMI and NMII in axenic media were detectable.

Among other Dot/Icm substrates with predicted effector functions (van Schaik et al., 2013), only three proteins were found to be differentially regulated in this study. Two plasmid encoded proteins, CBUA0013 (Voth et al., 2011), and CBUA0023 (Voth et al., 2011), were observed upregulated in NMI compared to NMII during propagation in L-929 as well as in ACCM-D. In contrast, CBU_2078 (Chen et al., 2010) was observed in higher amounts in NMI compared to NMII during growth in L-929 cells and in ACCM-D. Out of over a 100 described T4BSS effector proteins (McDonough et al., 2012; Qiu and Luo, 2017), only 9 (CBU_0021, CBU_0175, CBU_0447, CBU_0794, CBU_0937, CBU_1379a, CBU_1425, CBU_1751, and CBU_2078) were detected, but with no fold change of semi-quantitative expression. Of these, seven were identified in a large-scale screen for translocation in Legionella pneumophila, and two, CvpB and Cig57, have a functional assignment (Chen et al., 2010; Latomanski et al., 2016; Martinez et al., 2016).

\section{LPS-Associated Proteins}

The LPS is an amphiphilic OM structure with a hydrophobic lipid A membrane anchor, a core oligosaccharide, and highly variable $\mathrm{O}$-specific polysaccharide chain (OPS). The exact structure and biosynthetic pathway of the LPS was not fully elucidated yet. Under all three conditions tested, several proteins associated with biosynthesis of the lipid A ( $\mathrm{LpxABCDH})$ and core oligosaccharide residues 3-deoxy-D-manno-oct-2-ulosonic acid (Kdo, KdsAB) and D-glycero-D-manno-heptose (Hep, GmhA, HldE, CBU_1996, CBU_0678) were detected. However, we did not detect any proteins from the OPS-associated genomic region CBU_0679 to CBU_0698 (deleted region in NMII), as well as in axenic media or in the cell-based cultures in NMI proteomes. This negative observation is especially interesting as these genes and their protein products are supposed to be a key genetic difference of NMI and NMII.

\section{DISCUSSION}

We used a combination of MS-based shotgun proteomics and LFQ approach for semi-quantitative analysis of proteomes of two closely related C. burnetii isolates, NMI, and NMII, under three different growth conditions. Namely, cell-free propagation in a complex (ACCM-2) and/or defined (ACCM-D) acidified citrate cysteine medium was compared to growth in L-929 mouse fibroblasts. The dominant difference between these two isolates 
TABLE 3 | Overview of selected C. burnetii proteins involved in secretion systems in axenic media and cell culture.

\begin{tabular}{|c|c|c|c|c|c|c|c|c|}
\hline & Locus & Protein & Function & \multicolumn{3}{|c|}{ NMI to NMII } & $\begin{array}{c}\text { NMI } \\
\text { ACCM-D to } \\
\text { ACCM-2 }\end{array}$ & $\begin{array}{c}\text { NMII } \\
\begin{array}{c}\text { ACCM-D to } \\
\text { ACCM-2 }\end{array}\end{array}$ \\
\hline \multirow[t]{8}{*}{ Sec translocon } & CBU_0147 & SecA & Protein translocase subunit & 1.22 & 1.15 & 1.42 & 0.86 & 0.81 \\
\hline & CBU_0258 & $\mathrm{SecY}$ & Protein translocase subunit & 0.45 & 0.62 & 0.51 & 1.60 & 2.22 \\
\hline & CBU_0450 & Ffh & Signal recognition particle (SRP) subunit FFH/SRP54 & 0.20 & 2.28 & 0.89 & 0.19 & 2.19 \\
\hline & CBU_1142 & SecD & Protein translocase subunit & 2.12 & 1.04 & 1.38 & 3.11 & 1.53 \\
\hline & CBU_1143 & YajC & Protein translocase subunit & 4.73 & 4.80 & 2.12 & 0.80 & 0.81 \\
\hline & CBU_1504 & LepB-1 & Signal peptidase I & 0.83 & 0.84 & 2.07 & 2.09 & 2.10 \\
\hline & CBU_1519 & SecB & Protein export chaperone & 0.74 & 0.93 & 2.53 & 0.62 & 0.79 \\
\hline & CBU_1903 & FtsY & Cell division protein, SRP receptor & 1.60 & 2.06 & 0.98 & 0.63 & 0.82 \\
\hline \multirow{9}{*}{ Secreted proteins } & CBU_0482 & & Arginine-binding protein & 25.40 & 0.35 & 1.08 & 9.77 & 0.14 \\
\hline & CBU_0562a & & Unknown protein & 14474.49 & 0.02 & 0.89 & 421.07 & 0.00 \\
\hline & CBU_0630 & Mip & Macrophage infectivity potentiator & 11.65 & 0.63 & 1.67 & 3.86 & 0.21 \\
\hline & CBU_0915 & EnhB.1 & Enhanced entry protein & 19.05 & 0.17 & 6.76 & 26.48 & 0.23 \\
\hline & CBU_1095 & & Hypothetical exported protein & 151.52 & 1.32 & 0.60 & 18.27 & 0.16 \\
\hline & CBU_1137 & EnhB.2 & Enhanced entry protein & 41080.90 & 0.04 & 0.69 & 3973.96 & 0.00 \\
\hline & CBU_1138 & EnhA.4 & Enhanced entry protein & 13997.48 & 0.02 & 8.57 & 4324.11 & 0.01 \\
\hline & CBU_1173 & & Unknown protein & 36.47 & 1.99 & 3.51 & 1.66 & 0.09 \\
\hline & CBU_1404 & & Hypothetical exported protein & 15851.24 & 2.13 & 7.03 & 35.90 & 0.00 \\
\hline
\end{tabular}

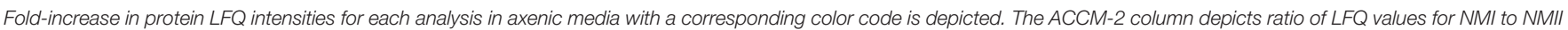

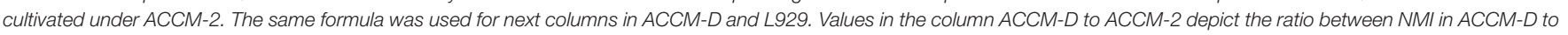

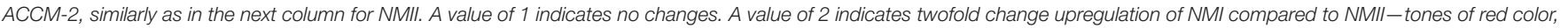

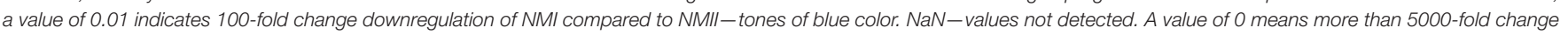
downregulation of NMI compared to NMII (the values are rounded).

is the severe truncation of the LPS in NMII associated with a large chromosomal deletion (Hoover et al., 2002). The published genome sequences of both isolates indicate small changes in the genome (partial deletions of homologs of CBU_0678, CBU_0698, and CBU_0918 and several SNPs) (Seshadri et al., 2003; Millar et al., 2017), which may lead to gross changes in the proteome. Together, this may cause pleiotropic phenotypes. The severe truncation of the LPS in NMII and increased amount of phospholipids (Frimmelová et al., 2016) in the outer membrane could lead to increased membrane fluidity. This increases the permeability for lipophilic compounds and affects correct insertion of OMPs into the membrane (Nikaido, 2003).

Both isolates were grown to a cell density of $\sim 1 \mathrm{E}+07$ to $1 \mathrm{E}+08 \mathrm{GE} / \mathrm{ml}$, which was reached on day 7 in ACCM-2 and day 10 in ACCM-D. In addition, persistently infected L-929 mouse fibroblasts were used for comparison. The unlimited number of compared groups with the LFQ technique enables a semiquantitative investigation of the proteomes. The applicability of this workflow was shown by hierarchical clustering (Figure 1C) and PCA (Figure 1D). Both methods generated six distinctive groups encompassing each biological triplicate of axenic or cell culture propagated bacteria. Previously published comparative studies either were based on gel electrophoresis (Skultety et al., 2011) or did not involve virulent phase I bacteria (Papadioti et al., 2012). The only proteomic study comparing NMI and NMII in embryonated hen eggs was qualitative (Skultety et al., 2011). Our semi-quantitative comparative analysis fills the gap between the previously published genome-wide transcriptional study and proteomic data (Kuley et al., 2015b).

Changes in the proteome profiles of NMI and NMII, under the conditions applied here, became only observable after application of stringent statistics (ANOVA significance for axenic and Student's $t$-test significance for infected L-929 samples). Overall, the highest amount of semi-quantifiable proteins was obtained from ACCM-D grown bacteria, followed by ACCM2 and cell culture propagated bacteria. This clearly reveals the feasibility of the applied approach for a comparative analysis of closely related isolates. The involvement of two different time points (7 and 10 days for ACCM-2 and ACCM-D, respectively) and a persistently infected cell culture can introduce artificial conditions and potentially results in altered proteome profiles between the 7 th and 10th day of infection, but comparable cell densities were reached at the selected time points. In order to follow only the most prominent proteomic changes, this 
part of study was performed in pentaplicates/hexaplicates for NMI and NMII, respectively. Furthermore, a stringent statistical workflow was applied. In summary, the L929 infection model showed substantial numbers of semi-quantifiable proteins and confirmed the higher relevancy of the ACCM-D medium. However, harvesting the cells at different time points, improved protocols for isolation of the bacteria and optimizing the sample preparation protocol could lead to a better comparability and a higher number of identifiable and semi-quantifiable proteins.

Comparing global differences between axenic media and cellbased cultures, the type of the media (ACCM-2 or ACCM-D) had a great impact on the difference of the proteome as demonstrated in a previously published transcriptomic study (Kuley et al., 2015b). A bigger overlap of regulated proteins was observed for ACCM-D and cell culture grown bacteria in contrast to ACCM-2, as shown in Figure 1E. This supports the relevance of ACCM-D not only as a growth medium but also as a CCV-like environment without host stress. Process mapping showed that most proteins were assigned to cellular and metabolic pathways for all three conditions tested (Figure 1A).

From the biological processes identified, proteins involved in stress response, Sec-dependent and T4BSS-dependent secretion, and LPS biosynthesis are of prominent interest. In ACCM-2 and ACCM-D, bacteria reach the late logarithmic or early stationary phase after 7 or 10 days, respectively (Omsland et al., 2011; Sandoz et al., 2016a). This was indicated for NMI in comparison to NMII in ACCM-D by downregulation of the translational machinery, including ribosomal proteins and translational initiation/elongation factors. Indeed, the ribosome-associated inhibitor A (RaiA, CBU_0020), which maintains translation accuracy during stress or upon entry into the stationary phase, was upregulated (Ueta et al., 2005). Of the translational regulators, CsrA1 (CBU0024) and CsrA2 (CBU_1050), which play an important role during shifting from exponential growth to stress survival, only CsrA2 is upregulated in NMI propagated in ACCM-D. The same upregulation of CsrA2 was observed by Sandoz et al. (2016b), for NMII propagated for up to 21 days in Vero cells (Romeo et al., 2013; Sandoz et al., 2016b). In addition, caseinolytic proteases (Clp, chaperon), such as ClpA and ClpPlike proteins CBU_0353, CBU_1483, and CBU_1538, were upregulated. They play an important role during stress response by assisting in proteolysis and disaggregation of proteins. For example, Salmonella typhimurium clpA and $c l p B$ mutants are highly sensitive against high temperature and oxidative stress (Sangpuii et al., 2018). Downregulation of Fis and RpoD, two exponential phase transcription factors, and upregulation of RpoS and its regulator SpoT point to stationary growth of NMI in ACCM-D. These data correlate with gene expression data during morphological differentiation from LCV to SCV (Sandoz et al., 2016b). In addition, the ScvA, a typical SCVassociated protein, was strongly upregulated in NMI after 10 days in ACCM-D (Coleman et al., 2004, 2007). These data imply the entry into the stationary phase and may indicate morphological differentiation (Moormeier et al., 2019). In contrast, the amount of semi-quantifiable proteins in ACCM-2 and L-929 propagated bacteria was much lower and not sufficient to identify a specific growth phase.
Interestingly, NMI, and NMII respond differently with regard to oxidative stress in ACCM-2 and ACCM-D. Previously, it was shown on the transcriptional level that first-generation ACCM1 is associated with significant upregulation of genes involved in defenses against oxidative stress in NMII (Sandoz et al., 2014). Subsequent substitution of fetal bovine serum for methyl$\beta$-cyclodextrin in ACCM-2 reduced this response, promoted developmental transition, and increased viability (Sandoz et al., 2014). Similar to ACCM-1, we observed upregulation of both superoxide dismutases (SodB, SodC), both reductases (AhpC1, AhpC2), as well as OxyR as stress response regulator in NMI compared to NMII in ACCM-2. These proteins are necessary for the direct detoxification of oxygen radicals (Mertens and Samuel, 2012; Brennan et al., 2015). In addition, repair of oxidized proteins by glutathione (radical sink) and the peroxiredoxin Bcp are upregulated in NMI.

In ACCM-D, direct detoxification and the repair of oxidized proteins are not upregulated in NMI. Instead, upregulation of a glycine betaine transport system, CBU_0177/CBU_0178 and a $\mathrm{Na} 2+/ \mathrm{H}+$ antiporter (NhaP.1) was observed. Enhanced import of glycine betaine protects against hyperosmotic stress (Pham et al., 2018). NhaP.1 is a $\mathrm{Na} 2+/ \mathrm{H}+$ antiporter that extrudes sodium in exchange for external protons. This implies that osmoregulation is important for NMI in ACCM-D, whereas direct detoxification is more relevant in ACCM-2. C. burnetii has a highly basic theoretical proteome with an average $\mathrm{pI}$ value for all predicted CDSs of 8.25. It was suggested that this basic proteome counterbalances the acidic environment of the CCV (Seshadri et al., 2003; Ihnatko et al., 2012). This implies that ACCM-D is not a harsh environment, which only requires osmoregulation.

For NMII, these data lead to the conclusion that both media represent a similar high oxidative stress environment. There are no major differences visible, when comparing NMII grown in ACCM-2 with ACCM-D (Table 3). The main difference between both $C$. burnetii isolates is the severe truncation of the LPS in NMII (Toman and Skultéty, 1996). The LPS is essential for Gram-negative bacteria. It functions as a permeability barrier for small hydrophobic compounds, salts, and detergents. Thus, it allows bacteria to survive in harsh environments and might explain the observed different response of NMI and NMII (Zhang et al., 2013).

The control mechanism of T4BSS is executed at the transcriptional level by the two-component regulatory system PmrAB (CBU_1277 and CBU_1278). It directly regulates the Dot/Icm secretion system in L. pneumophila (McPhee et al., 2003) and C. burnetii (van Schaik et al., 2013; Beare et al., 2014). The here observed upregulation of PmrAB in NMI in cellbased experiments corresponds well with a previously published transcriptomic study (Kuley et al., 2015a). Also, the upregulation determined in this study of many T4BSS components in NMI in cell-based experiments fits in with the high PmrAB activity. Seven previously identified T4BSS effector proteins were detected in this study. Only two of them, CvpB and Cig57, have a functional assignment (Chen et al., 2010; Latomanski et al., 2016; Martinez et al., 2016).

RND efflux pumps are associated with excretion of poisonous metal ions and AcrB-like efflux pumps (acrAB) with protection 
against hydrophobic inhibitors in E. coli (Ma et al., 1995). The observed upregulation of RND efflux pumps and uptake of osmolytes (TamAB) during propagation in L-929 and ACCM$\mathrm{D}$ might represent a novel survival mechanism for $C$. burnetii within the CCV.

Contrary to the proposed prominent role of genes in the OPSassociated genomic region, CBU_0679 to CBU_0698 (deleted region in NMII), none of these proteins were observed under axenic or cell-based cultivation in NMI. The apparent absence of these proteins in NMI could be due to a very low expression level under the limit of detection of mass spectrometry, rather than by the absence of expression. These proteomic findings are in concordance with previous studies-none of the proteins were detected after cultivation in VERO cells for NMI and C. burnetii Q212 (Papadioti et al., 2011, 2012), respectively (Sandoz et al., 2016b). However, some proteins of the OPS-associated genomic region were observable on the proteomic level during propagation in embryonated hen eggs: CBU_0681, CBU_0682, CBU_0683 (dihydroxystreptose), CBU_0690, and CBU_0691 (virenose) (Flores-Ramirez et al., 2014). This might be due to massive replication of $C$. burnetii during egg propagation and a higher amount of bacterial proteins in the according samples. An improvement of bacterial protein isolation and implementation of more sensitive proteomic methods will enhance the analytical sensitivity. This might allow one to follow regulation of protein expression of OPS-associated genes.

Overall, the data presented here show the successful application of an MS-based LFQ approach for semi-quantitative analysis of $C$. burnetii proteomes under different growth conditions. It was demonstrated that the proteome profiles differ according to growth conditions and growth phase. Furthermore, differences in the response to oxidative stress were shown for C. burnetii Nine Mile isolates. Major traits necessary for the intracellular lifestyle, such as proteins putatively involved in the Sec translocation and T4BSS, were detected during axenic cultivation. The approach established in this study allows for complex and sensitive analyses of protein expression profiles in various $C$. burnetii isolates and preparations. It might allow for a future analysis of isolate-specific virulence traits. Although the data presented in this pilot study are promising, their confirmations via other proteomic-based techniques like targeted mass spectrometry or Western blot are needed.

\section{REFERENCES}

Andoh, M., Russell-Lodrigue, K. E., Zhang, G., and Samuel, J. E. (2005). Comparative virulence of phase I and II Coxiella burnetii in immunodeficient mice. Ann. N. Y. Acad. Sci. 1063, 167-170. doi: 10.1196/annals.1355.026

Angelakis, E., and Raoult, D. (2010). Q fever. Vet. Microbiol. 140, 297-309. doi: 10.1016/j.vetmic.2009.07.016

Beare, P. A., Jeffrey, B. M., Long, C. M., Martens, C. M., and Heinzen, R. A. (2018). Genetic mechanisms of Coxiella burnetii lipopolysaccharide phase variation. PLoS Pathog. 14:e1006922. doi: 10.1371/journal.ppat.1006922

Beare, P. A., Sandoz, K. M., Larson, C. L., Howe, D., Kronmiller, B., and Heinzen, R. A. (2014). Essential role for the response regulator PmrA in Coxiella burnetii type 4B secretion and colonization of mammalian host cells. J. Bacteriol. 196, 1925-1940. doi: 10.1128/JB.01532-14

\section{DATA AVAILABILITY}

The mass spectrometry proteomics data have been deposited to the ProteomeXchange Consortium via the PRIDE (PerezRiverol et al., 2019) partner repository with the dataset identifier PXD013224 (https://www.ebi.ac.uk/pride/archive/ projects/PXD013224).

\section{AUTHOR CONTRIBUTIONS}

JD and KM-S designed the experiments. JD, KM-S, JK, and PP wrote the manuscript. GS participated in the genome quantification of prepared samples. JD, KM-S, and PP prepared the samples. JK conducted the mass spectrometry analyses. BS, $\mathrm{AF}, \mathrm{JD}, \mathrm{MC}$, and KM-S performed analysis of data. All authors discussed the results and reviewed the manuscript.

\section{FUNDING}

This LFQ mass spectrometry work was supported by funding from projects of the Ministry of Interior, Czech Republic (VH20172020012: Preparation of the collection of biologically significant toxins with the support of European biological European biodefence laboratory network) and by Ministry of Defence of the Czech Republic through a Long-term organization development plan 907930101413. The mass spectrometry analysis was supported by the Ministry of Defence of the Czech Republic (Long-term organization development plan Medical Aspects of Weapons of Mass Destruction). The bioinformatic analyses were supported by the institutional support projects MO1012 and SVV 260369. This project is part of the Q-GAPS Project (Q feverGerman Interdisciplinary Program for Research) funded by the Federal Ministry of Education and Research (BMBF) under project number 01KI1726C, Research Network Zoonotic Infectious Diseases.

\section{SUPPLEMENTARY MATERIAL}

The Supplementary Material for this article can be found online at: https://www.frontiersin.org/articles/10.3389/fmicb. 2019.02022/full\#supplementary-material

Boarbi, S., Mori, M., Rousset, E., Sidi-Boumedine, K., Van Esbroeck, M., and Fretin, D. (2014). Prevalence and molecular typing of Coxiella burnetii in bulk tank milk in belgian dairy goats, 2009-2013. Vet. Microbiol. 170, 117-124. doi: 10.1016/j.vetmic.2014.01.025

Brennan, R. E., Kiss, K., Baalman, R., and Samuel, J. E. (2015). Cloning, expression, and characterization of a Coxiella burnetii $\mathrm{Cu} / \mathrm{Zn}$ superoxide dismutase. BMC Microbiol. 15. doi: 10.1186/s12866-015-0430-8

Briggs, H. L., Pul, N., Seshadri, R., Wilson, M. J., Tersteeg, C., Russell-Lodrigue, K. E., et al. (2008). Limited role for iron regulation in Coxiella burnetii pathogenesis. Infect. Immun. 76, 2189-2201. doi: 10.1128/IAI.01609-07

Chen, C., Banga, S., Mertens, K., Weber, M. M., Gorbaslieva, I., Tan, Y., et al. (2010). Large-scale identification and translocation of type IV secretion substrates by Coxiella burnetii. Proc. Natl. Acad. Sci. U.S.A. 107, 21755-21760. doi: 10.1073/pnas.1010485107 
Chmielewski, T., Sidi-Boumedine, K., Duquesne, V., Podsiadly, E., Thiéry, R., and Tylewska-Wierzbanowska, S. (2009). Molecular epidemiology of Q fever in Poland. Pol. J. Microbiol. 58, 9-13.

Coleman, S. A., Fischer, E. R., Cockrell, D. C., Voth, D. E., Howe, D., Mead, D. J., et al. (2007). Proteome and antigen profiling of Coxiella burnetii developmental forms. Infect. Immun. 75, 290-298. doi: 10.1128/IAI.00883-06

Coleman, S. A., Fischer, E. R., Howe, D., Mead, D. J., and Heinzen, R. A. (2004). Temporal analysis of Coxiella burnetii morphological differentiation. J. Bacteriol. 186, 7344-7352. doi: 10.1128/JB.186.21.73447352.2004

Cox, J., Hein, M. Y., Luber, C. A., Paron, I., Nagaraj, N., and Mann, M. (2014). Accurate proteome-wide label-free quantification by delayed normalization and maximal peptide ratio extraction, termed MaxLFQ. Mol. Cell. Proteomics. 13, 2513-2526. doi: 10.1074/mcp.M113.031591

Cox, J., Neuhauser, N., Michalski, A., Scheltema, R. A., Olsen, J. V., and Mann, M. (2011). Andromeda: a peptide search engine integrated into the MaxQuant environment. J. Proteome Res. 10, 1794-1805. doi: 10.1021/pr1 01065j

Flores-Ramirez, G., Jankovicova, B., Bilkova, Z., Miernyk, J. A., and Skultety, L. (2014). Identification of Coxiella burnetii surface-exposed and cell envelope associated proteins using a combined bioinformatics plus proteomics strategy. Proteomics 14, 1868-1881. doi: 10.1002/pmic. 201300338

Frangoulidis, D., Walter, M. C., Antwerpen, M., Zimmermann, P., Janowetz, B., Alex, M., et al. (2014). Molecular analysis of Coxiella burnetii in Germany reveals evolution of unique clonal clusters. Int. J. Med. Microbiol. 304, 868-876. doi: 10.1016/j.ijmm.2014.06.011

Frimmelová, M., Toman, R., Pompach, P., and Škultéty, L. (2016). Modifications in the glycerophospholipid composition between the Coxiella burnetii phase I and phase II cells suggest an association with phase variation of the bacterium. Acta Virol. 60, 27-33. doi: 10.4149/av_2016_01_27

Ftácek, P., Skultéty, L., and Toman, R. (2000). Phase variation of Coxiella burnetii strain priscilla: influence of this phenomenon on biochemical features of its lipopolysaccharide. J. Endotoxin Res. 6, 369-376. doi: $10.1177 / 09680519000060050701$

Graham, J. G., MacDonald, L. J., Hussain, S. K., Sharma, U. M., Kurten, R. C., and Voth, D. E. (2013). Virulent Coxiella burnetii pathotypes productively infect primary human alveolar macrophages. Cell. Microbiol. 15, 1012-1025. doi: $10.1111 / \mathrm{cmi} .12096$

Hackstadt, T., Peacock, M. G., Hitchcock, P. J., and Cole, R. L. (1985). Lipopolysaccharide variation in Coxiella burnetti: intrastrain heterogeneity in structure and antigenicity. Infect. Immun. 48, 359-365.

Heinzen, R. A., Frazier, M. E., and Mallavia, L. P. (1992). Coxiella burnetii superoxide dismutase gene: cloning, sequencing, and expression in Escherichia coli. Infect. Immun. 60, 3814-3823.

Hendrix, L. R., Samuel, J. E., and Mallavia, L. P. (1991). Differentiation of Coxiella burnetii isolates by analysis of restriction-endonucleasedigested DNA separated by SDS-PAGE. J. Gen. Microbiol. 137, 269-276. doi: 10.1099/00221287-137-2-269

Hicks, L. D., Raghavan, R., Battisti, J. M., and Minnick, M. F. (2010). A DNA-binding peroxiredoxin of Coxiella burnetii is involved in countering oxidative stress during exponential-phase growth. J. Bacteriol. 192, 2077-2084. doi: 10.1128/JB.01324-09

Hill, J., and Samuel, J. E. (2011). Coxiella burnetii acid phosphatase inhibits the release of reactive oxygen intermediates in polymorphonuclear leukocytes. Infect. Immun. 79, 414-420. doi: 10.1128/IAI. 01011-10

Hoover, T. A., Culp, D. W., Vodkin, M. H., Williams, J. C., and Thompson, H. A. (2002). Chromosomal DNA deletions explain phenotypic characteristics of two antigenic variants, phase II and RSA 514 (crazy), of the Coxiella burnetii nine mile strain. Infect. Immun. 70, 6726-6733. doi: 10.1128/IAI.70.12.6726-2733.2002

Howe, D., Shannon, J. G., Winfree, S., Dorward, D. W., and Heinzen, R. A. (2010). Coxiella burnetii phase I and II variants replicate with similar kinetics in degradative phagolysosome-like compartments of human macrophages. Infect. Immun. 78, 3465-3474. doi: 10.1128/IAI.00406-10

Ihnatko, R., Shaw, E., and Toman, R. (2012). Proteome of Coxiella burnetii. Adv. Exp. Med. Biol. 984, 105-130. doi: 10.1007/978-94-007-4315-1_6
Klee, S. R., Tyczka, J., Ellerbrok, H., Franz, T., Linke, S., Baljer, G., et al. (2006). Highly sensitive real-time PCR for specific detection and quantification of Coxiella burnetii. BMC Microbiol. 6:2. doi: 10.1186/1471-2180-6-2

Kuley, R., Bossers-deVries, R., Smith, H. E., Smits, M. A., Roest, H. I. J., and Bossers, A. (2015a). Major differential gene regulation in Coxiella burnetii between in vivo and in vitro cultivation models. BMC Genom. 16:953. doi: 10.1186/s12864-015-2143-7

Kuley, R., Smith, H. E., Frangoulidis, D., Smits, M. A., Jan Roest, H. I., and Bossers, A. (2015b). Cell-free propagation of Coxiella burnetii does not affect its relative virulence. PLOS ONE. 10:e0121661. doi: 10.1371/journal.pone. 0121661

Larson, C. L., Beare, P. A., Howe, D., and Heinzen, R. A. (2013). Coxiella burnetii effector protein subverts clathrin-mediated vesicular trafficking for pathogen vacuole biogenesis. Proc. Natl. Acad. Sci. U.S.A. 110, E4770-E4779. doi: 10.1073/pnas.1309195110

Latomanski, E. A., Newton, P., Khoo, C. A., and Newton, H. J. (2016). The effector Cig57 hijacks FCHO-mediated vesicular trafficking to facilitate intracellular replication of Coxiella burnetii. PLoS Pathog. 12:e1006101. doi: 10.1371/journal.ppat.1006101

Luedtke, B. E., Mahapatra, S., Lutter, E. I., and Shaw, E. I. (2017). The Coxiella burnetii type IVB secretion system (T4BSS) component DotA is released/secreted during infection of host cells and during in vitro growth in a T4BSS-dependent manner. Pathog. Dis. 75, 1-17. doi: 10.1093/femspd/ $\mathrm{ftx} 047$

Ma, D., Cook, D. N., Alberti, M., Pon, N. G., Nikaido, H., and Hearst, J. E. (1995). Genes acrA and acrB encode a stress-induced efflux system of Escherichia coli. Mol. Microbiol. 16, 45-55. doi: 10.1111/j.1365-2958.1995. tb02390.x

Mansilla Pareja, M. E., Bongiovanni, A., Lafont, F., and Colombo, M. I. (2017). Alterations of the Coxiella burnetii replicative vacuole membrane integrity and interplay with the autophagy pathway. Front. Cell. Infect. Microbiol. 7:112. doi: $10.3389 /$ fcimb.2017.00112

Martinez, E., Allombert, J., Cantet, F., Lakhani, A., Yandrapalli, N., Neyret, A., et al. (2016). Coxiella burnetii effector CvpB modulates phosphoinositide metabolism for optimal vacuole development. Proc. Natl. Acad. Sci. U.S.A. 113, E3260-E3269. doi: 10.1073/pnas.1522811113

Maurin, M., and Raoult, D. (1999). Q fever. Clin. Microbiol. Rev. 12, 518-553. doi: 10.1128/CMR.12.4.518

McCaul, T. F., Banerjee-Bhatnagar, N., and Williams, J. C. (1991). Antigenic differences between Coxiella burnetii cells revealed by postembedding immunoelectron microscopy and immunoblotting. Infect. Immun. 59, 3243-3253.

McDonough, J. A., Newton, H. J., and Roy, C. R. (2012). Coxiella burnetii secretion systems. Adv. Exp. Med. Biol. 984, 171-197. doi: 10.1007/978-94-007-4315-1_9

McPhee, J. B., Lewenza, S., and Hancock, R. E. W. (2003). Cationic antimicrobial peptides activate a two-component regulatory system, PmrA-PmrB, that regulates resistance to polymyxin $\mathrm{B}$ and cationic antimicrobial peptides in Pseudomonas aeruginosa. Mol. Microbiol. 50, 205-217. doi: 10.1046/j.1365-2958.2003.03673.x

Megger, D. A., Bracht, T., Meyer, H. E., and Sitek, B. (2013). Label-free quantification in clinical proteomics. Biochim. Biophys. Acta BBA Proteins Proteomics 1834, 1581-1590. doi: 10.1016/j.bbapap.2013.04.001

Mertens, K., Lantsheer, L., Ennis, D. G., and Samuel, J. E. (2008). Constitutive SOS expression and damage-inducible AddAB-mediated recombinational repair systems for Coxiella burnetii as potential adaptations for survival within macrophages. Mol. Microbiol. 69, 1411-1426. doi: 10.1111/j.1365-2958.2008.06373.x

Mertens, K., and Samuel, J. E. (2012). Defense mechanisms against oxidative stress in Coxiella burnetii: adaptation to a unique intracellular niche. Adv. Exp. Med. Biol. 984, 39-63. doi: 10.1007/978-94-007-4315-1_3

Mi, H., Muruganujan, A., and Thomas, P. D. (2013). PANTHER in 2013: Modeling the evolution of gene function, and other gene attributesin the context of phylogenetic trees. Nucleic Acids Res. 41, D377-D386. doi: 10.1093/nar/ gks1118

Millar, J. A., Beare, P. A., Moses, A. S., Martens, C. A., Heinzen, R. A., and Raghavan, R. (2017). Whole-genome sequence of Coxiella burnetii nine mile RSA439 (Phase II, Clone 4), a laboratory workhorse strain. Genome Announc. 5:e00471-17. doi: 10.1128/genomeA.00471-17 
Moffatt, J. H., Newton, P., and Newton, H. J. (2015). Coxiella burnetii: turning hostility into a home. Cell. Microbiol. 17, 621-631. doi: 10.1111/cmi.12432

Moormeier, D. E., Sandoz, K. M., Beare, P. A., Sturdevant, D. E., Nair, V., Cockrell, D. C., et al. (2019). Coxiella burnetii RpoS regulates genes involved in morphological differentiation and intracellular growth. J. Bacteriol. 201:e00009-19. doi: 10.1128/JB.00009-19

Nikaido, H. (2003). Molecular basis of bacterial outer membrane permeability revisited. Microbiol. Mol. Biol. Rev. 67, 593-656. doi: 10.1128/MMBR.67.4.593-656.2003

Omsland, A., Beare, P. A., Hill, J., Cockrell, D. C., Howe, D., Hansen, B., et al. (2011). Isolation from animal tissue and genetic transformation of Coxiella burnetii are facilitated by an improved axenic growth medium. Appl. Environ. Microbiol. 77, 3720-3725. doi: 10.1128/AEM.02826-10

Omsland, A., Cockrell, D. C., Howe, D., Fischer, E. R., Virtaneva, K., Sturdevant, D. E., et al. (2009). Host cell-free growth of the $\mathrm{Q}$ fever bacterium Coxiella burnetii. Proc. Natl. Acad. Sci. U.S.A. 106, 4430-4434. doi: 10.1073/pnas.0812074106

Papadioti, A., De Bock, P.-J., Vranakis, I., Tselentis, Y., Gevaert, K., Psaroulaki, A., et al. (2012). Study of the whole cell lysate of two Coxiella burnetii strains using N-terminomics. J. Proteome Res. 11, 3150-3159. doi: 10.1021/pr201175m

Papadioti, A., Markoutsa, S., Vranakis, I., Tselentis, Y., Karas, M., Psaroulaki, A., et al. (2011). A proteomic approach to investigate the differential antigenic profile of two Coxiella burnetii strains. J. Proteomics 74, 1150-1159. doi: 10.1016/j.jprot.2011.04.016

Perez-Riverol, Y., Csordas, A., Bai, J., Bernal-Llinares, M., Hewapathirana, S., Kundu, D. J., et al. (2019). The PRIDE database and related tools and resources in 2019: Improving support for quantification data. Nucleic Acids Res. 47, D442-D450. doi: 10.1093/nar/gky1106

Pham, H. T., Nhiep, N. T. H., Vu, T. N. M., Huynh, T. N., Zhu, Y., Huynh, A. L. D., et al. (2018). Enhanced uptake of potassium or glycine betaine or export of cyclic-di-AMP restores osmoresistance in a high cyclic-di-AMP Lactococcus lactis mutant. PLoS Genet. 14:e1007574. doi: 10.1371/journal.pgen.1007574

Qiu, J., and Luo, Z.-Q. (2017). Legionella and coxiella effectors: strength in diversity and activity. Nat. Rev. Microbiol. 15, 591-605. doi: $10.1038 /$ nrmicro.2017.67

Roest, H. I. J., Ruuls, R. C., Tilburg, J. J. H. C., Nabuurs-Franssen, M. H., Klaassen, C. H. W., Vellema, P., et al. (2011). Molecular epidemiology of Coxiella burnetii from ruminants in Q fever outbreak, the Netherlands. Emerg. Infect. Dis. 17, 668-675. doi: 10.3201/eid1704. 101562

Romeo, T., Vakulskas, C. A., and Babitzke, P. (2013). Post-transcriptional regulation on a global scale: form and function of Csr/Rsm systems. Environ. Microbiol. 15, 313-324. doi: 10.1111/j.1462-2920.2012. 02794.x

Russell-Lodrigue, K. E., Andoh, M., Poels, M. W. J., Shive, H. R., Weeks, B. R., Zhang, G. Q., et al. (2009). Coxiella burnetii isolates cause genogroup-specific virulence in mouse and guinea pig models of acute Q fever. Infect. Immun. 77, 5640-5650. doi: 10.1128/IAI.00851-09

Samoilis, G., Aivaliotis, M., Vranakis, I., Papadioti, A., Tselentis, Y., Tsiotis, G., et al. (2010). Proteomic screening for possible effector molecules secreted by the obligate intracellular pathogen Coxiella burnetii. J. Proteome Res. 9, 1619-1626. doi: $10.1021 /$ pr900605q

Samoilis, G., Psaroulaki, A., Vougas, K., Tselentis, Y., and Tsiotis, G. (2007). Analysis of whole cell lysate from the intercellular bacterium Coxiella burnetii using two gel-based protein separation techniques. J. Proteome Res. 6, 3032-3041. doi: 10.1021/pr070077n

Sanchez, S. E., Vallejo-Esquerra, E., and Omsland, A. (2018). Use of axenic culture tools to study Coxiella burnetii. Curr. Protoc. Microbiol. 50:e52. doi: $10.1002 /$ cpmc.52

Sandoz, K. M., Beare, P. A., Cockrell, D. C., and Heinzen, R. A. (2016a). Complementation of arginine auxotrophy for genetic transformation of Coxiella burnetii by use of a defined axenic medium. Appl. Environ. Microbiol. 82, 3042-3051. doi: 10.1128/AEM.00 261-16

Sandoz, K. M., Popham, D. L., Beare, P. A., Sturdevant, D. E., Hansen, B., Nair, V., et al. (2016b). Transcriptional profiling of Coxiella burnetii reveals extensive cell wall remodeling in the small cell variant developmental form. PLOS ONE 11:e0149957. doi: 10.1371/journal.pone.01 49957
Sandoz, K. M., Sturdevant, D. E., Hansen, B., and Heinzen, R. A. (2014). Developmental transitions of Coxiella burnetii grown in axenic media. J. Microbiol. Methods 96, 104-110. doi: 10.1016/j.mimet.2013.11.010

Sangpuii, L., Dixit, S. K., Kumawat, M., Apoorva, S., Kumar, M., Kappala, D., et al. (2018). Comparative roles of clpA and $\mathrm{clpB}$ in the survival of S. typhimurium under stress and virulence in poultry. Sci. Rep. 8:4481. doi: 10.1038/s41598-018-22670-6

Schäfer, W., Eckart, R. A., Schmid, B., Cagköylü, H., Hof, K., Muller, Y. A., et al. (2017). Nuclear trafficking of the anti-apoptotic Coxiella burnetii effector protein AnkG requires binding to p32 and Importin- $\alpha 1$. Cell. Microbiol. 19. doi: $10.1111 / \mathrm{cmi} .12634$

Seshadri, R., Hendrix, L. R., and Samuel, J. E. (1999). Differential expression of translational elements by life cycle variants of Coxiella burnetii. Infect. Immun. 67, 6026-6033.

Seshadri, R., Paulsen, I. T., Eisen, J. A., Read, T. D., Nelson, K. E., Nelson, W. C., et al. (2003). Complete genome sequence of the Q-fever pathogen Coxiella burnetii. Proc. Natl. Acad. Sci. U.S.A. 100, 5455-5460. doi: 10.1073/pnas.0931379100

Siemsen, D. W., Kirpotina, L. N., Jutila, M. A., and Quinn, M. T. (2009). Inhibition of the human neutrophil NADPH oxidase by Coxiella burnetii. Microbes Infect. 11, 671-679. doi: 10.1016/j.micinf.2009.04.005

Skultety, L., Hajduch, M., Flores-Ramirez, G., Miernyk, J. A., Ciampor, F., Toman, R., et al. (2011). Proteomic comparison of virulent phase I and avirulent phase II of Coxiella burnetii, the causative agent of Q fever. J. Proteomics 74, 1974-1984. doi: 10.1016/j.jprot.2011.05.017

Skultety, L., Hernychova, L., Toman, R., Hubalek, M., Slaba, K., Zechovska, J., et al. (2005). Coxiella burnetii whole cell lysate protein identification by mass spectrometry and tandem mass spectrometry. Ann. N. Y. Acad. Sci. 1063, 115-122. doi: 10.1196/annals.1355.019

Smith, P. K., Krohn, R. I., Hermanson, G. T., Mallia, A. K., Gartner, F. H., Provenzano, M. D., et al. (1985). Measurement of protein using bicinchoninic acid. Anal. Biochem. 150, 76-85. doi: 10.1016/0003-2697(85)9 0442-7

Thomas, P. D. (2003). PANTHER: a library of protein families and subfamilies indexed by function. Genome Res. 13, 2129-2141. doi: 10.1101/gr. 772403

Toman, R., and Skultéty, L. (1996). Structural study on a lipopolysaccharide from Coxiella burnetii strain nine mile in avirulent phase II. Carbohydr. Res. 283, 175-185. doi: 10.1016/0008-6215(96)87610-5

Ueta, M., Yoshida, H., Wada, C., Baba, T., Mori, H., and Wada, A. (2005). Ribosome binding proteins $\mathrm{YhbH}$ and YfiA have opposite functions during $100 \mathrm{~S}$ formation in the stationary phase of Escherichia coli. Genes Cells Devoted Mol. Cell. Mech. 10, 1103-1112. doi: 10.1111/j.1365-2443.2005.0 0903.x

van Schaik, E. J., Chen, C., Mertens, K., Weber, M. M., and Samuel, J. E. (2013). Molecular pathogenesis of the obligate intracellular bacterium Coxiella burnetii. Nat. Rev. Microbiol. 11, 561-573. doi: 10.1038/nrmicro3049

Varghees, S., Kiss, K., Frans, G., Braha, O., and Samuel, J. E. (2002). Cloning and porin activity of the major outer membrane protein P1 from Coxiella burnetii. Infect. Immun. 70, 6741-6750. doi: 10.1128/IAI.70.12.6741-67 50.2002

Voth, D. E., Beare, P. A., Howe, D., Sharma, U. M., Samoilis, G., Cockrell, D. C., et al. (2011). The Coxiella burnetii cryptic plasmid is enriched in genes encoding type IV secretion system substrates. J. Bacteriol. 193, 1493-1503. doi: 10.1128/JB.01359-10

Voth, D. E., and Heinzen, R. A. (2007). Lounging in a lysosome: the intracellular lifestyle of Coxiella burnetii. Cell. Microbiol. 9, 829-840. doi: 10.1111/j.1462-5822.2007.0 0901.x

Wang, Z., Wang, J., Ren, G., Li, Y., and Wang, X. (2015). Influence of core oligosaccharide of lipopolysaccharide to outer membrane behavior of Escherichia coli. Mar. Drugs 13, 3325-3339. doi: 10.3390/md130 63325

Weber, M. M., Faris, R., van Schaik, E. J., and Samuel, J. E. (2018). Identification and characterization of arginine finger-like motifs, and endosome-lysosome basolateral sorting signals within the Coxiella burnetii type IV secreted effector protein CirA. Microbes Infect. 20, 302-307. doi: 10.1016/j.micinf.2017. 12.013 
Wiśniewski, J. R., Zougman, A., and Mann, M. (2009). Combination of FASP and stagetip-based fractionation allows in-depth analysis of the hippocampal membrane proteome. J. Proteome Res. 8, 5674-5678. doi: 10.1021/pr9 $00748 \mathrm{n}$

Yu, Y.-Q., Gilar, M., Lee, P. J., Bouvier, E. S. P., and Gebler, J. C. (2003). Enzyme-friendly, mass spectrometry-compatible surfactant for in-solution enzymatic digestion of proteins. Anal. Chem. 75, 6023-6028. doi: 10.1021/ac0 346196

Zamboni, D. S., McGrath, S., Rabinovitch, M., and Roy, C. R. (2003). Coxiella burnetii express type IV secretion system proteins that function similarly to components of the Legionella pneumophila Dot/Icm system. Mol. Microbiol. 49, 965-976. doi: 10.1046/j.1365-2958.2003.0 3626.x

Zhang, G., Meredith, T. C., and Kahne, D. (2013). On the essentiality of lipopolysaccharide to Gram-negative bacteria. Curr. Opin. Microbiol. 16, 779-785. doi: 10.1016/j.mib.2013.09.007
Zhang, G., Russell-Lodrigue, K. E., Andoh, M., Zhang, Y., Hendrix, L. R., and Samuel, J. E. (2007). Mechanisms of vaccine-induced protective immunity against Coxiella burnetii infection in BALB/c mice. J. Immunol. Baltim. Md. 179, 8372-8380. doi: 10.4049/jimmunol.179.12.8372

Conflict of Interest Statement: The authors declare that the research was conducted in the absence of any commercial or financial relationships that could be construed as a potential conflict of interest.

Copyright (C) 2019 Dresler, Klimentova, Pajer, Salovska, Fucikova, Chmel, Schmoock, Neubauer and Mertens-Scholz. This is an open-access article distributed under the terms of the Creative Commons Attribution License (CC BY). The use, distribution or reproduction in other forums is permitted, provided the original author(s) and the copyright owner(s) are credited and that the original publication in this journal is cited, in accordance with accepted academic practice. No use, distribution or reproduction is permitted which does not comply with these terms. 